\title{
Erratum to: Different site, different clinical outcomes in perforated colorectal cancer?
}

\author{
Ping Song ${ }^{1}$ - Kaiqiang Qin ${ }^{1} \cdot$ Xiaona Chu ${ }^{1} \cdot$ Shikuan $\mathrm{Li}^{1}$
}

Published online: 17 August 2016

(C) Springer-Verlag Berlin Heidelberg 2016

Erratum to: Int J Colorectal Dis (2016) 31:1517-1518

DOI 10.1007/s00384-016-2534-5

This article was unintentionally published twice in this journal, by the same authors. Following should be considered the version of record and be used for citation purposes:

Song P, Qin K, Chu X, Li S (2016) Different site, different clinical outcomes in perforated colorectal cancer? Int J Colorectal Dis 31(6):1483-1484. doi:10.1007/s00384-016-2529-2

The duplicate "Song P, Qin K, Chu X, Li S (2016) Different site, different clinical outcomes in perforated colorectal cancer? Int J Colorectal Dis 31(6):1517-1518. doi:10.1007/ s00384-016-2534-5" is to be ignored.

The Editorial Office of International Journal of Colorectal Disease apologizes to the readers of the journal for not detecting the duplication during the publication process.

The online version of the original article can be found at http://dx.doi. org/10.1007/s00384-016-2534-5.

Shikuan Li

worldwidth@aliyun.com

1 Affiliated Hospital of Qingdao University, Qingdao, China 